\title{
Risk Factors for Major Adverse Events after Surgical Closure of Ventricular Septal Defect in Patients Less than 1 Year of Age: A Single-Center Retrospective
}

\author{
Servet Ergün'1, MD; Serhat Bahadır Genç ${ }^{1}$, MD; Okan Yildiz'1 MD; Erkut Öztürk², MD; Hasan Candaş Kafalı², MD; \\ Pelin Ayyıldız², MD; Sertaç Haydin' ${ }^{1}$, MD
}

DOI: 10.21470/1678-9741-2018-0299

\begin{abstract}
Objective: To reveal the risk factors that can lead to a complicated course and an increased morbidity in patients < 1 year old after surgical ventricular septal defect (VSD) closure.

Methods: We reviewed a consecutive series of patients who were admitted to our institution for surgical VSD closure who were under one year of age, between 2015 and 2018. Mechanical ventilation (MV) time $>\mathbf{2 4}$ hours, intensive care unit (ICU) stay longer than three days, and hospital stay longer than seven days were defined as "prolonged". Unplanned reoperation, complete heart block requiring a permanent pacemaker implantation, sudden circulatory arrest, and death were considered as significant major adverse events (MAE).

Results: VSD closure was performed in 185 patients. The median age was five (1-12) months. There was prolonged MV time in $54(29.2 \%)$ patients. Four patients $(2.2 \%)$ required
\end{abstract}

permanent pacemaker implantation. Hemodynamically significant residual VSD was observed in six $(3.2 \%)$ patients. Extracorporeal membrane oxygenation-cardiopulmonary resuscitation was performed in one $(0.5 \%)$ patient. Small age $(<4$ months) $(P$-value $<0.001)$ and prolonged cardiopulmonary bypass time $(P=0.03)$ were found to delay extubation and to prolong MV time. Low birth weight at the operation was associated with MAE $(P=0.03)$.

Conclusion: Higher body weight during operation had a reducing effect on the MAE frequency and shortened the MV duration, ICU stay, and hospital stay. As a conclusion, for patients who are scheduled to undergo VSD closure, body weight should be taken into consideration.

Keywords: Ventricular Heart Septal Defect. Cardiopulmonary Bypass. Intensive Care Units. Risk Factors. Length of Stay.

Abbreviations, acronyms \& symbols

$\begin{array}{ll}\text { ACC } & =\text { Aortic cross-clamp } \\ \text { ASD } & =\text { Atrial septal defect } \\ \text { AV } & =\text { Atrioventricular } \\ \text { CHF } & =\text { Congestive heart failure } \\ \mathrm{CI} & =\text { Confidence interval } \\ \mathrm{CPB} & =\text { Cardiopulmonary bypass } \\ \mathrm{CPR} & =\text { Cardiopulmonary resuscitation } \\ \mathrm{E}-\mathrm{CPR} & =\text { ECMO-cardiopulmonary resuscitation } \\ \mathrm{ECMO} & =\text { Extracorporeal membrane oxygenation } \\ \text { ICU } & =\text { Intensive care unit } \\ \text { LBW } & =\text { Low birth weight }\end{array}$

'Department of Pediatric Cardiovascular Surgery, Istanbul Saglik Bilimleri University, Istanbul Mehmet Akif Ersoy Thoracic and Cardiovascular Surgery Education and Research Hospital, Istanbul, Turkey.

${ }^{2}$ Department of Pediatric Cardiology, Istanbul Saglik Bilimleri University, Istanbul Mehmet Akif Ersoy Thoracic and Cardiovascular Surgery Education and Research Hospital, Istanbul, Turkey.

This study was carried out at the Istanbul Mehmet Akif Ersoy Egitim Arastirma Hastanesi, Istanbul, Turkey.
LOS
$=$ Length of stay
MAE = Major adverse events
MV = Mechanical ventilation
OR = Odds ratio
PAB = Pulmonary artery banding
PDA = Patent ductus arteriosus
PHT = Pulmonary hypertension
SD = Standard deviation
SPSS = Statistical Package for the Social Sciences
VSD $\quad=$ Ventricular septal defect
VT $=$ Ventilation time

Correspondence Address:

Servet Ergün

iD https://orcid.org/0000-0002-4504-6825

Department of Pediatric Cardiovascular Surgery, Istanbul Saglik Bilimleri University, Istanbul Mehmet Akif Ersoy Thoracic and Cardiovascular Surgery Education and Research Hospital

Turgut Özal Bulv 11, Istanbul, Turkey - Zip Code: 34303

E-mail: drservetergun41@gmail.com 


\section{INTRODUCTION}

The most common congenital heart defect is the ventricular septal defect (VSD). Thus, the surgical closure of VSD is the most common pediatric cardiac procedure performed around the world ${ }^{[1-3]}$. Most VSDs that are surgically repaired are perimembranous VSDs ${ }^{[4]}$. In the last two decades, advances in surgical techniques and in postoperative patient care have led to a decrease in postoperative mortality and morbidity ${ }^{[5-7]}$. However, there are still risks of a complicated course due to heart block, reoperation due to residual defects, prolonged mechanical ventilation (MV), and prolonged intensive care unit (ICU) and hospital stays. Despite a lack of worldwide consensus, most studies have found that a low birth weight (LBW) at the time of the operation and a young age $(<6$ months) are related to morbidity ${ }^{[6]}$. However, Schipper et al. reported that these two factors were associated with a prolonged ventilation time (VT) and ICU and hospital stays, although there was no increase in complication rates ${ }^{[8]}$.

In this paper, we revealed the risk factors that can lead to a complicated course and an increased morbidity in patients $<1$ year old after surgical VSD closure.

\section{METHODS}

We reviewed a consecutive series of patients who were $<1$ year old and underwent surgical VSD closure between January 2015 and February 2018. This retrospective study was approved by the institutional Ethics Committee and was conducted in accordance with the principles of the Declaration of Helsinki. Patients were included in the study if they had a simple VSD, VSD with atrial septal defect (ASD), VSD with patent ductus arteriosus (PDA), VSD with mild pulmonary stenosis, or a previous pulmonary banding operation.

The VSDs were divided into perimembranous, muscular, and doubly committed defects. Patients with other pathologies were excluded from the study. Preoperative demographic data, previous history, surgical data, perfusion data, clinical follow-up, and preoperative and postoperative echocardiography reports were evaluated for each patient retrospectively.

In our routine, each patient had an echocardiographic examination before and after the procedure in the operating room. Preoperative cardiac catheterization was not performed on any patient. The indications for surgery were congestive heart failure (CHF), pulmonary hypertension (PHT), and PHT with CHF. None of the patients in this study who underwent surgery had aortic valve insufficiency.

Postoperative outcomes and complications were assessed and included the length of hospital and ICU stays, duration of $M V$, postcardiotomy syndrome, renal failure, chylothorax, temporary or permanent complete heart block, neurological events, sudden circulatory collapse, diaphragmatic paralysis, postoperative extracorporeal membrane oxygenation (ECMO) support, readmission to hospital, and death ${ }^{[9]}$. The duration of MV was considered to be prolonged if it lasted more than 24 hours; an extended ICU or hospital stay lasted longer than three days and seven days, respectively. Significant major adverse events (MAE) included unplanned reoperations, complete heart blocks requiring implantation of a permanent pacemaker, sudden cardiac arrest, and death.

\section{Surgical Technique}

All patients underwent a standardized median sternotomy and a cardiopulmonary bypass (CPB) maintained by aortic and selective caval cannulation. Del Nido cardioplegia solution was used after aortic cross-clamp (ACC) for cardiac protection. All VSDs were closed using a native pericardial patch and running suture technique. During the operation, ASD closure, PDA ligation, pulmonary artery debanding, and tricuspid valve plasty were also performed if necessary.

\section{Statistical Analysis}

Statistical analyses were performed using the Statistical Package for the Social Sciences (SPSS) software (version 22.0). The normal distribution of the variables was evaluated using visual (histogram and probability graphs) and analytical (Kolmogorov-Smirnov test and Shapiro-Wilk test) methods. A descriptive analysis was performed using frequency tables for the categorical variables; means and standard deviations were used to describe the normally distributed variables. Medians and ranges were used to describe the variables with a non-normal distribution. During the univariate analysis of the predictive risk factor for the outcome variables, univariate predictors were determined. Variables with a $P$-value $<0.05$ in the univariate analysis that were not correlated with each other were included in the multivariate logistic regression analysis. Variables with $P<0.05$ were considered to be significantly related to outcomes.

\section{RESULTS}

VSD closure was performed in 185 patients. The demographic characteristics of the patients are demonstrated in Table 1. The median age was five months (1-12 months); 98 patients (53\%) were male and $87(47 \%)$ were female. The median body weight of the patients was $5.4 \mathrm{~kg}(2.8-10.5 \mathrm{~kg})$ at the time of operation. The most common defect was perimembranous VSD $(n=167$, $90.3 \%)$, followed by muscular VSD ( $n=14,7.6 \%)$, and doubly committed VSD ( $n=4,2.2 \%)$. However, 16 (8.6\%) patients had additional muscular VSDs.

The most common indication for surgery was PHT ( $n=128$, 69.2\%), followed by CHF $(n=46,24.9 \%)$ and PHT and CHF $(n=11$, 5.9\%). The most frequent concomitant cardiac defects were ASD $(n=36,19.5 \%)$ and PDA $(n=17,3.2 \%)$. Preoperatively, nine patients (4.9\%) with CHF were receiving MV support. Genetic anomalies were present in 68 patients (36.8\%); the most common genetic anomaly was Down syndrome $(n=58,31.4 \%)$.

Examination of the patients' operative data showed that the mean duration of CPB was $86.0 \pm 22.8$ minutes and the mean ACC time was $60.2 \pm 17.6$ minutes (Table 1). Prolonged MV occurred in 54 patients (29.2\%), while 77 patients (41.6\%) had a prolonged stay in the ICU, and 84 patients (45.4\%) had a delayed discharge.

Pulmonary complications, such as atelectasis, pleural effusion, bronchospasm, and pneumothorax, were most frequent $(n=19,10.2 \%)$, followed by heart rhythm problems $(n=17,9.2 \%)$, including transient or permanent atrioventricular 
Table 1. Patients' baseline characteristics and operative variables.

\begin{tabular}{|c|c|c|}
\hline \multicolumn{2}{|l|}{ Variables } & Patients (N:185) \\
\hline \multicolumn{2}{|l|}{ Age (month), median (min-max) } & $5(1-12)$ \\
\hline \multicolumn{2}{|c|}{ Weight (kg), median (min-max) } & $5.4(2.8-10.5)$ \\
\hline \multicolumn{2}{|c|}{ Body surface area $\left(\mathrm{m}^{2}\right)$, median (min-max) } & $0.3(0.18-0.48)$ \\
\hline \multicolumn{2}{|c|}{ Female, n (\%) } & $87(47.0)$ \\
\hline \multirow{3}{*}{ Type of VSD, n (\%) } & Perimembranous & $167(90.3)$ \\
\hline & Muscular & $14(7.6)$ \\
\hline & Doubly committed & $4(2.2)$ \\
\hline \multirow{3}{*}{ Indication for VSD closure, n (\%) } & Pulmonary hypertension (PHT) & $128(69.2)$ \\
\hline & Congestive heart failure (CHF) & $46(24.9)$ \\
\hline & Both PHT and CHF & $11(5.9)$ \\
\hline \multirow{8}{*}{ Concomitant cardiac defects, n (\%) } & Atrial septal defect (ASD) & $36(19.5)$ \\
\hline & Patent ductus arteriosus (PDA) & $17(9.2)$ \\
\hline & Both ASD and PDA & $9(4.9)$ \\
\hline & Additional muscular VSD & $16(8.6)$ \\
\hline & Patent foramen ovale & $21(11.4)$ \\
\hline & Shunt between left ventricle and right atrium & $9(4.9)$ \\
\hline & Mitral regurgitation & $8(4.3)$ \\
\hline & Aortic valve prolapse & $2(1.1)$ \\
\hline \multicolumn{2}{|l|}{ Preoperative MV support, n (\%) } & $9(4.9)$ \\
\hline \multirow{2}{*}{ Genetic syndrome, n (\%) } & Down & $58(31.4)$ \\
\hline & Others & $10(5.4)$ \\
\hline \multicolumn{2}{|c|}{ Aristotle basic score, mean \pm SD } & $6.0 \pm 0.0$ \\
\hline \multicolumn{2}{|c|}{ Aristotle comprehensive score, mean \pm SD } & $6.6 \pm 0.9$ \\
\hline \multicolumn{2}{|c|}{ Preoperative hematocrit value, median (min-max) } & $33.6(25.1-46.1)$ \\
\hline \multicolumn{2}{|c|}{ Hypothermia $\left({ }^{\circ} \mathrm{C}\right)$, mean $\pm \mathrm{SD}$} & $32.8 \pm 1.8$ \\
\hline \multicolumn{2}{|l|}{ Bypass time (min), mean $\pm S D$} & $86.0 \pm 22.8$ \\
\hline \multicolumn{2}{|c|}{ Aortic cross-clamp time (min), mean \pm SD } & $60.2 \pm 17.6$ \\
\hline
\end{tabular}

$\mathrm{MV}=$ mechanical ventilation; $\mathrm{SD}=$ standard deviation; $\mathrm{VSD}=$ ventricular septal defect

(AV) block and junctional ectopic tachycardia. Four patients (2.2\%) required a permanent pacemaker. Six patients (3.2\%) had a hemodynamically significant residual VSD.

One patient (0.5\%) received ECMO and cardiopulmonary resuscitation (CPR). The cause of circulatory collapse was pulmonary hypertensive crisis. The patient was successfully withdrawn from ECMO and discharged. No neurological deficit was observed in any patient (Table 2).

A multivariable model was used to assess the association between a patient's characteristics and the risk of MAE, prolonged MV time, or prolonged ICU or hospital stay (Tables 3 and 4). According to the model, LBW at the time of the operation was associated with a MAE (odds ratio [OR] 0.45, 95\% confidence interval [CI] 22-0.93, and $P=0.03)$. The MAE frequency was lower in males than in females (OR 0.17, 95\% Cl 0.03-0.89, and $P=0.03$ ). Age ( $<4$ months) and prolonged CPB time were found to delay extubation and to prolong MV (OR 3.94, 95\% Cl 1.96$7.90, P<0.001$ and $\mathrm{OR} 1.01,95 \% \mathrm{Cl} 1.00-1.03, P=0.03$, respectively). Patients who underwent surgery because of PHT had a lower MV time (OR 0.27, 95\% Cl 0.10-0.77, $P=0.01$ ) than the others. An extended ICU stay was associated with patients who had a long CPB time and a high Aristotle comprehensive complexity score (OR 1.01, 95\% Cl 1.00-1.02, $P=0.05$ and OR 1.78, 95\% Cl 1.14-2.77, $P=0.01$, respectively). However, a high body weight at the time of the operation shortened the ICU stay (OR 0.59, 95\% Cl 0.44-0.78, $P<0.001)$.

Two patients (1.1\%) with CHF had a postoperative decrease in the left ventricular ejection fraction. The left ventricular functions 
Table 2. Postoperative outcomes.

\begin{tabular}{|c|c|c|}
\hline \multicolumn{2}{|l|}{ Variables } & Patients (N: 185) \\
\hline \multicolumn{2}{|c|}{ Ventilation time (h), median (min-max) } & $17(1-216)$ \\
\hline \multicolumn{2}{|l|}{$\leq 24 \mathrm{~h}, \mathrm{n}(\%)$} & $131(70.8)$ \\
\hline \multicolumn{2}{|l|}{$>24 \mathrm{~h}, \mathrm{n}(\%)$} & $54(29.2)$ \\
\hline \multicolumn{2}{|c|}{ ICU LOS (day), median (min-max) } & $3(1-120)$ \\
\hline \multicolumn{2}{|l|}{$\leq 3 \mathrm{~d}, \mathrm{n}(\%)$} & $108(58.8)$ \\
\hline \multicolumn{2}{|l|}{$>3 d, n(\%)$} & $77(41.6)$ \\
\hline \multicolumn{2}{|c|}{ Postoperative LOS (day), median (min-max) } & $7(5-27)$ \\
\hline \multicolumn{2}{|l|}{$\leq 7 \mathrm{~d}, \mathrm{n}(\%)$} & $101(54.6)$ \\
\hline \multicolumn{2}{|l|}{$>7 \mathrm{~d}, \mathrm{n}(\%)$} & $84(45.4)$ \\
\hline \multicolumn{2}{|c|}{ Delayed sternal closure, n (\%) } & $4(2.2)$ \\
\hline \multicolumn{2}{|c|}{ Reintubation, n (\%) } & $12(6.5)$ \\
\hline \multirow{3}{*}{ Arrhythmia, n (\%) } & Junctional ectopic tachycardia & $10(5.4)$ \\
\hline & Permanent complete AV block & $4(2.2)$ \\
\hline & Transient complete AV block & $3(1.6)$ \\
\hline \multicolumn{2}{|l|}{ Infection, n (\%) } & $10(5.4)$ \\
\hline \multicolumn{2}{|l|}{ Neurological event, $(\%)^{*}$} & - \\
\hline \multirow{4}{*}{ Respiratory event, n (\%) } & Pulmonary atelectasis & $8(4.3)$ \\
\hline & Pneumothorax & $7(3.8)$ \\
\hline & Bronchospasm & $3(1.6)$ \\
\hline & Pleural effusion & $1(0.5)$ \\
\hline \multicolumn{2}{|l|}{ Renal failure, $n(\%)^{*}$} & - \\
\hline \multicolumn{2}{|l|}{ Wound infection, n (\%) } & $2(1.1)$ \\
\hline \multicolumn{2}{|c|}{ Need for treatment of pulmonary hypertension, n (\%) } & $9(4.9)$ \\
\hline \multicolumn{2}{|c|}{ Decrease in left ventricular functions } & $2(1.1)$ \\
\hline \multicolumn{2}{|l|}{ Need for ECMO, n (\%) } & $1(0.5)$ \\
\hline \multicolumn{2}{|c|}{ Reoperation for residual VSD, n (\%) } & $6(3.2)$ \\
\hline \multicolumn{2}{|l|}{ Rehospitalization, n (\%) } & $2(1.1)$ \\
\hline \multicolumn{2}{|l|}{ Death, n (\%) } & - \\
\hline \multicolumn{2}{|l|}{ Major adverse event, n (\%) } & $11(5.94)$ \\
\hline \multicolumn{2}{|l|}{ Total complications, n (\%) } & $62(33.5)$ \\
\hline
\end{tabular}

*Renal dysfunction: Requiring temporary or permanent dialysis; neurological event: persisting at discharge.

$\mathrm{AV}=$ atrioventricular; $\mathrm{ECMO}=$ extracorporeal membrane oxygenation; ICU=intensive care unit; $\mathrm{LOS}=$ length of stay; $\mathrm{VSD}=\mathrm{ventricular}$ septal defect

were improved with medical treatment and the patients were discharged. One patient had a double-chamber pacemaker implanted due to a complete AV block. Eleven patients (5.94\%) experienced a MAE, excluding death; these patients are listed in Table 5. Of these 11 patients, six (3.2\%) patients underwent reoperation for residual VSD, four (2.2\%) had a permanent pacemaker implanted after being monitored for two weeks, and one had pulmonary hypertensive crisis, as previously mentioned. The mean body weight of the 11 patients was $4.7 \mathrm{~kg}$.
The mean follow-up period was $1.97 \pm 0.8$ years. Of the 185 patients, 55 (29.7\%) had a residual hemodynamically insignificant VSD $(<3 \mathrm{~mm})$, which closed spontaneously on its own in 47 patients (85.45\%) during the follow-up period. The remaining eight patients did not have a long-term follow-up.

\section{DISCUSSION}

Currently, surgical VSD closure is performed successfully in many centers with zero mortality and a low rate of complications. 
Table 3. Univariate analysis for major adverse event, prolonged ventilation time, prolonged intensive care unit (ICU) stay time, and prolonged hospital stay time.

\begin{tabular}{|c|c|}
\hline Major adverse event & $P$-value \\
\hline \multicolumn{2}{|l|}{ Variables } \\
\hline Weight & 0.04 \\
\hline Gender (male) & 0.05 \\
\hline Type of VSD & 0.05 \\
\hline Mechanical ventilation time & $P$-value \\
\hline \multicolumn{2}{|l|}{ Variables } \\
\hline Age (<4 months) & $<0.001$ \\
\hline Weight & $<0.001$ \\
\hline Indication of PHT & 0.02 \\
\hline Preoperative intubation & 0.02 \\
\hline Aristotle comprehensive score & 0.05 \\
\hline CPB time & 0.05 \\
\hline ICU stay time & $P$-value \\
\hline \multicolumn{2}{|l|}{ Variables } \\
\hline Age & 0.01 \\
\hline Weight & $<0.001$ \\
\hline Preoperative intubation & 0.04 \\
\hline Aristotle comprehensive score & 0.002 \\
\hline CPB time & 0.01 \\
\hline ACC time & 0.01 \\
\hline Hospital stay time & $P$-value \\
\hline \multicolumn{2}{|l|}{ Variables } \\
\hline Age & 0.05 \\
\hline Weight & 0.003 \\
\hline Aristotle comprehensive score & 0.02 \\
\hline CPB time & 0.01 \\
\hline
\end{tabular}

$\mathrm{ACC}=$ aortic cross-clamp; $\mathrm{CPB}=$ cardiopulmonary bypass; $\mathrm{PHT}=$ pulmonary hypertension; $\mathrm{VSD}=$ ventricular septal defect

However, mortality and prolonged ICU and hospital stays are still reported due to complications. Reoperation rates for residual VSDs are between $0 \%$ and $4.6 \%$, while pacemaker implantation rates are $0-5.6 \%$ and mortality rates are $0-2.8 \% \%^{[5-8,10,11]}$ (Table 6).

In this retrospective analysis, surgical VSD closures were performed with zero mortality and a low rate of MAE. The reoperation rate for residual VSD was $3.2 \%$ and the permanent pacemaker implantation rate was $2.2 \%$. We found out that our MAE rate (5.9\%) was slightly higher than the ones presented by Anderson et al. ${ }^{[6]}$ (5.3\%) and Schipper et al. ${ }^{[8]}$ (2.9\%). However, the previous reports concentrated on the outcomes of the surgical management of
VSDs in children regardless of age, while the present paper focused solely on VSD closure in patients $<1$ year of age.

Cardiac operations have become feasible and safe for young patients and patients with LBW because of improvements in surgical techniques and perfusion technology with good cardiac protection. Although some reports have demonstrated that LBW and age ( $<6$ months) are associated with morbidity, there is no consensus on this issue.

Kogon et al. ${ }^{[1]}$ reported that the body weight did not affect the duration of the operation, $\mathrm{ACC}, \mathrm{CPB}$, and $\mathrm{MV}$; in addition, body weight did not affect the development of complications 
Table 4. Multivariate analysis to determine independent predictive factors of major adverse events, postoperative ventilation, and intensive care unit (ICU) and hospital stay times.

\begin{tabular}{l|l|c|c|c|c}
\hline \multicolumn{2}{l|}{ Dependent variables and predictive factors } & Odds ratio & $\mathbf{9 5 \% ~ C l ~ l o w e r ~}$ & $\begin{array}{c}\mathbf{9 5 \%} \mathrm{Cl} \\
\text { upper }\end{array}$ & P-value \\
\hline Major adverse event & Weight & 0.45 & 0.22 & 0.93 & 0.03 \\
\hline & Male & 0.17 & 0.03 & 0.89 & 0.03 \\
\hline Prolonged ventilation time & $\leq 4$ months & 3.94 & 1.96 & 7.90 & $<0.001$ \\
\hline & Indication of PHT & 0.27 & 0.10 & 0.77 & 0.01 \\
\hline & CPB time & 1.01 & 1.00 & 1.03 & 0.03 \\
\hline Prolonged ICU stay & Weight & 0.59 & 0.44 & 0.78 & $<0.001$ \\
\hline & Aristotle comprehensive score & 1.78 & 1.14 & 2.77 & 0.01 \\
\hline Prolonged hospital stay & CPB time & 1.01 & 1.00 & 1.02 & 0.05 \\
\hline & Weight & 0.69 & 0.53 & 0.89 & 0.005 \\
\hline
\end{tabular}

$\mathrm{Cl}=$ confidence interval; $\mathrm{CPB}=$ cardiopulmonary bypass; $\mathrm{PHT}=$ pulmonary hypertension

or the length of ICU or hospital stay. Similarly, Schipper et al. ${ }^{[8]}$ showed that LBW did not lead to any complications despite prolonged hospital stay, VT, and ICU stay.

Schipper et al. also showed that Down syndrome was related to the duration of MV and ICU stay ${ }^{[8]}$. In the present study, 68 patients (36.8\%) had a genetic syndrome; as expected, Down syndrome was the most common. Contrary to the report by Schipper et al., we found out that genetic syndromes were not risk factors for the development of $\operatorname{MAE}(P=0.16)$, prolonged MV time $(P=0.66)$, prolonged ICU stay $(P=0.17)$, or prolonged hospital stay $(P=0.38)$.

Aydemir et al. ${ }^{[7]}$ emphasized that mortality was higher in patients $>3$ months of age than in those under this age, although there was no significant difference in morbidity between age groups. Anderson et al. ${ }^{[6]}$ showed that for patients $<6$ months old, every extra kilogram of weight at the time of operation shortened their ICU stay by about 2.3 days. Additionally, they reported that for every kilogram loss in body weight, the complication rate increased 1.8 times $^{[6]}$. A body weight of $<4$ $\mathrm{kg}$ was found to be a risk factor for complete heart block ${ }^{[12]}$. In accordance with these previous studies, we concluded that an increase in body weight reduced the risk of MAE (OR 0.45, 95\% $\mathrm{Cl} 0.22-0.93, P=0.03)$, and shortened the ICU stay (OR 0.59, 95\% Cl $0.44-0.78, P<0.001$ ) and hospital stay (OR 0.69, 95\% Cl 0.53-0.89, $P=0.005)$. We also showed that being $<4$ months of age was a risk factor for prolonged MV time (OR 3.94, 95\% Cl 1.96-7.90, $P<0.001)$.

To predict the mortality and morbidities associated with surgical VSD closure, different scoring systems are used ${ }^{[13]}$. As expected, the Aristotle comprehensive scores were high in patients who had a long ICU stay: OR 1.78, 95\% CI 1.14-2.77, and $P=0.01$. We could not compare our result with previous studies because there was no similar study in the literature.
Studies have reported the residual VSD rates to be 16 $51 \%[8,10]$ and the spontaneous closure rate to be approximately $71 \%$ within a three-year follow-up period ${ }^{[8]}$. In the present study, $29.7 \%$ of the patients had a residual hemodynamically insignificant VSD $(<3 \mathrm{~mm})$ and $85.4 \%(n=47)$ of these VSDs closed spontaneously within a mean follow-up period of $1.97 \pm 0.8$ years. The moderately high insignificant residual VSD rate might be due to the post-CPB epicardial echocardiography routine ${ }^{[14]}$. This agreed with the conclusions by Schipper et al. ${ }^{[8]}$ who used transesophageal echocardiography.

Thus, the results of the present study supported the surgical closure of an isolated VSD in infants as a safe and effective therapy.

\section{Limitations}

The most important limitations of the present study were its retrospective nature and that it was a single-center study. If the total number of patients and associated complications were considered, the incidence of MAE might be affected. Thus, a study of a large series of patients or multicenter studies could be more informative.

\section{CONCLUSION}

VSD repair is considered to be a safe procedure with a very low mortality rate. In this study, we found out that a high body weight at the time of the operation reduced the frequency of MAEs and shortened the duration of MV, ICU stay, and hospital stay. Genetic syndromes had no effect on MAE. The Aristotle comprehensive score was a useful tool to estimate postoperative outcomes. In conclusion, body weight should be taken into consideration for patients who are scheduled to undergo surgical VSD closure. 
Table 5. Major adverse events of 11 patients.

\begin{tabular}{|c|c|c|c|c|c|c|c|}
\hline $\begin{array}{l}\text { Patient's } \\
\text { number }\end{array}$ & $\begin{array}{c}\text { Age } \\
\text { (months) }\end{array}$ & $\begin{array}{l}\text { Weight } \\
\text { (kg) }\end{array}$ & VSD type & $\begin{array}{l}\text { CPB } \\
(\min )\end{array}$ & $\begin{array}{c}\text { Aristotle } \\
\text { comprehensive } \\
\text { score }\end{array}$ & Notes & Genetics \\
\hline 1 & 4 & 4.5 & $\begin{array}{l}\text { Perimembranous } \\
\text { large (from inlet } \\
\text { to outlet) }\end{array}$ & 101 & 7 & $\begin{array}{l}\text { Reoperated due to residual leak } \\
\text { from VSD patch at postoperative } \\
\qquad 2^{\text {nd }} \text { day. }\end{array}$ & Down \\
\hline 2 & 5 & 5.1 & $\begin{array}{c}\text { Perimembranous } \\
\text { large }\end{array}$ & 99 & 9 & $\begin{array}{l}\text { Sternum left open postoperatively } \\
\text { due to severe PHT, and closed at } \\
\text { postoperative } 1^{\text {st }} \text { day. Pacemaker } \\
\text { implanted at postoperative 10th } \\
\text { day due to complete AV block. }\end{array}$ & Down \\
\hline 3 & 3 & 5.5 & $\begin{array}{l}\text { Perimembranous } \\
\text { malalignment } \\
\text { large }\end{array}$ & 87 & 6 & $\begin{array}{l}\text { Pacemaker implanted at } \\
\text { postoperative } 12^{\text {th }} \text { day due to } \\
\text { complete AV block. }\end{array}$ & \\
\hline 4 & 3 & 5.1 & $\begin{array}{l}\text { Perimembranous } \\
\text { large (inlet) }\end{array}$ & 101 & 8 & $\begin{array}{c}\text { Pacemaker implanted at } \\
\text { postoperative } 9^{\text {th }} \text { day due to } \\
\text { complete AV block. }\end{array}$ & Down \\
\hline 5 & 10 & 5.6 & $\begin{array}{c}\text { Perimembranous } \\
\text { large }\end{array}$ & 68 & 7 & $\begin{array}{l}\text { Reoperated due to residual leak } \\
\text { from VSD patch at postoperative } \\
\qquad 10^{\text {th }} \text { day. }\end{array}$ & Down \\
\hline 6 & 4.5 & 4.5 & $\begin{array}{c}\text { Perimembranous } \\
\text { large (inlet) }\end{array}$ & 81 & 6 & $\begin{array}{l}\text { Reoperated due to residual leak } \\
\text { from VSD patch at postoperative } \\
\qquad 6^{\text {th }} \text { day. }\end{array}$ & \\
\hline 7 & 4 & 3.5 & $\begin{array}{c}\text { Perimembranous } \\
\text { large }\end{array}$ & 67 & 9 & $\begin{array}{l}\text { Reoperated due to residual leak } \\
\text { from VSD patch at postoperative } \\
\qquad 2^{\text {nd }} \text { day. }\end{array}$ & $\begin{array}{l}\text { Preterm, } \\
\text { DiGeorge }\end{array}$ \\
\hline 8 & 6 & 4 & $\begin{array}{l}\text { Perimembranous } \\
\text { malalignment } \\
\text { large }\end{array}$ & 77 & 6 & $\begin{array}{l}\text { Reoperated due to residual leak } \\
\text { from VSD patch at postoperative } \\
\qquad 2^{\text {nd }} \text { day. }\end{array}$ & \\
\hline 9 & 3 & 4.5 & Muscular large & 100 & 6 & $\begin{array}{l}\text { Reoperated due to residual leak } \\
\text { from VSD patch at postoperative } \\
\qquad 2^{\text {nd }} \text { day. }\end{array}$ & \\
\hline 10 & 5 & 5.9 & $\begin{array}{c}\text { Perimembranous } \\
\text { large }\end{array}$ & 111 & 6 & $\begin{array}{l}\text { Pacemaker implanted at } \\
\text { postoperative } 7^{\text {th }} \text { day due to } \\
\text { complete AV block. }\end{array}$ & Down \\
\hline 11 & 3 & 4 & $\begin{array}{l}\text { Perimembranous } \\
\text { large + additional } \\
\text { midmuscular } \\
\text { defect }\end{array}$ & 111 & 6 & $\begin{array}{l}\text { PAB was not performed at first } \\
\text { during the operation as the Qp/ } \\
\text { Qs ratio was 1, but after E-CPR at } \\
\text { ICU due to the arrest pioneered } \\
\text { by PHT crisis, PAB was performed } \\
\text { before weaning from ECMO. He was } \\
\text { discharged after weaning. }\end{array}$ & \\
\hline
\end{tabular}

$\mathrm{AV}=$ ventricular atrium; $\mathrm{CPB}=$ cardiopulmonary bypass; $\mathrm{E}-\mathrm{CPR}=\mathrm{ECMO}$-cardiopulmonary resuscitation; $\mathrm{ECMO}=\mathrm{extracorporeal}$ membrane oxygenation; ICU=intensive care unit; $\mathrm{PAB}=$ pulmonary artery banding; $\mathrm{PHT}=$ pulmonary hypertension; VSD=ventricular septal defect 
Table 6. Results of VSD closure (studies after 2006).

\begin{tabular}{|c|c|c|c|c|c|c|c|}
\hline Author & Year & $\mathbf{N}$ & $\begin{array}{c}\text { Complete heart } \\
\text { block (\%) }\end{array}$ & $\begin{array}{c}\text { Reoperation } \\
(\%)\end{array}$ & $\begin{array}{c}\text { CPR or E-CPR } \\
(\%)\end{array}$ & Mortality (\%) & $\begin{array}{c}\text { Major adverse } \\
\text { events (\%) }\end{array}$ \\
\hline Andersen et al. ${ }^{[5]}$ & 2006 & 996 & 0.7 & & & 1.5 & \\
\hline Kogon et al. ${ }^{[11]}$ & 2007 & 225 & 0 & & & 0 & \\
\hline Scully et al. ${ }^{[10]}$ & 2010 & 215 & 0 & 0 & & 1.4 & \\
\hline Anderson et al. ${ }^{[6]}$ & 2013 & 285 & 2.1 & 4.6 & & 1.7 & 5.3 \\
\hline Aydemir et al. ${ }^{[7]}$ & 2013 & 282 & $<0.01$ & 0.7 & & 2.8 & \\
\hline Schipper et al. ${ }^{[8]}$ & 2016 & 243 & 0.8 & 2.1 & 0 & 0 & 2.9 \\
\hline Present report et al. & 2018 & 185 & 2.2 & 3.2 & 0.5 & 0 & 5.9 \\
\hline
\end{tabular}

$\mathrm{CPR}=$ cardiopulmonary resuscitation; $\mathrm{E}-\mathrm{CPR}=$ extracorporeal membrane oxygenation-cardiopulmonary resuscitation; $\mathrm{VSD}=\mathrm{ventricular}$ septal defect

\section{No financial support. \\ No conflict of interest.}

\section{Authors' roles \& responsibilities}

SE Conception or design of the work; drafting the work; any part of the work is appropriately investigated and resolved; final approval of the version to be published

Drafting the work; any part of the work is appropriately investigated and resolved; final approval of the version to be published

OY Acquisition and analysis; any part of the work is appropriately investigated and resolved; final approval of the version to be published

EO Revising the work; any part of the work is appropriately investigated and resolved; final approval of the version to be published

HCK Conception or design of the work; revising the work; any part of the work is appropriately investigated and resolved; final approval of the version to be published

PA Revising the work; any part of the work is appropriately investigated and resolved; final approval of the version to be published

$\mathrm{SH} \quad$ Revising the work; any part of the work is appropriately investigated and resolved; final approval of the version to be published

\section{REFERENCES}

1. Cresti A, Cantinotti M, Stefanelli S, Solari M, D'Aiello I, Falorni S, et al. [Current incidence of congenital heart disease diagnosed in the first year of life: results of a 20-year registry with one-year follow-up and comparison with the literature]. G Ital Cardiol. 2018;19(6):379-85. doi:10.1714/2922.29371. Italian.
2. Xie D, Fang J, Liu Z, Wang H, Yang T, Sun Z, et al. Epidemiology and major subtypes of congenital heart defects in Hunan Province, China. Medicine. 2018;97(31):e11770. doi:10.1097/MD.0000000000011770.

3. van der Linde $D$, Konings EE, Slager MA, Witsenburg M, Helbing WA, Takkenberg JJ, et al. Birth prevalence of congenital heart disease worldwide: a systematic review and meta-analysis. J Am Coll Cardiol. 2011;58(21):2241-7. doi:10.1016/j.jacc.2011.08.025.

4. Eroğlu AG, Atik SU, Sengenc E, Cig G, Saltik IL, Oztunc F. Evaluation of ventricular septal defect with special reference to the spontaneous closure rate, subaortic ridge, and aortic valve prolapse II. Pediatr Cardiol. 2017;38(5):915-21. doi:10.1007/s00246-017-1597-6.

5. Andersen H, Leval MR, Tsang VT, Elliott MJ, Anderson RH, Cook AC. Is complete heart block after surgical closure of ventricular septum defects still an issue? Ann Thorac Surg. 2006;82(3):948-56. doi:10.1016/j. athoracsur.2006.04.030.

6. Anderson BR, Stevens KN, Nicolson SC, Gruber SB, Spray TL, Wernovsky $\mathrm{G}$, et al. Contemporary outcomes of surgical ventricular septal defect closure. J Thorac Cardiovasc Surg. 2013;145(3):641-7. doi:10.1016/j. jtcvs.2012.11.032.

7. Aydemir NA, Harmandar B, Karaci AR, Sasmazel A, Bolukcu A, Saritas T, et al. Results for surgical closure of isolated ventricular septal defects in patients under one year of age. J Card Surg. 2013;28(2):174-9. doi:10.1111/ jocs. 12073.

8. Schipper M, Slieker MG, Schoof PH, Breur JM. Surgical repair of ventricular septal defect; Contemporary results and risk factors for a complicated course. Pediatr Cardiol. 2017;38(2):264-70. doi:10.1007/s00246-016-1508-2.

9. Jacobs ML, O'Brien SM, Jacobs JP, Mavroudis C, Lacour-Gayet F, Pasquali SK, et al. An empirically based tool for analyzing morbidity associated with operations for congenital heart disease. J Thorac Cardiovasc Surg. 2013;145(4):1046-57. doi:10.1016/j.jtcvs.2012.06.029.

10. Scully BB, Morales DL, Zafar F, McKenzie ED, Fraser CD Jr, Heinle JS. Current expectations for surgical repair of isolated ventricular septal defects. Ann Thorac Surg. 2010;89(2):544-9; discussion 550-1. doi:10.1016/j. athoracsur.2009.10.057.

11. Kogon B, Butler H, Kirshbom P, Kanter K, McConnell M. Closure of symptomatic ventricular septal defects: how early is too early? Pediatr Cardiol. 2008;29(1):36-9. doi:10.1007/s00246-007-9016-z.

12. Siehr SL, Hanley FL, Reddy VM, Miyake CY, Dubin AM. Incidence and risk factors of complete atrioventricular block after operative ventricular septal 
defect repair. Congenit Heart Dis. 2014;9(3):211-5. doi:10.1111/chd.12110

13. Cavalcanti PE, Sá MP, Santos CA, Esmeraldo IM, Chaves ML, Lins RF, et al. Stratification of complexity in congenital heart surgery: comparative study of the risk adjustment for congenital heart surgery (RACHS-1) method, aristotle basic score and society of thoracic surgeons-european association for cardio-thoracic surgery (STS-EACTS) mortality score. Rev Bras Cir Cardiovasc. 2015;30(2):148-58. doi:10.5935/1678-9741.20150001. 14. Öztürk E, Tanıdır IC, Ayyıldız P, Gokalp S, Kafali HC, Sahin M, et al. The role of intraoperative epicardial echocardiography in pediatric cardiac surgery. Echocardiography. 2018;35(7):999-1004. doi:10.1111/echo.13874. 